\title{
Genetic Redundancy Enhances Problems of Beneficial Mutations
}

\author{
Haitham Talaat* \\ Civil Engineering, Egypt
}

Submission: March 1, 2017; Published: April 25, 2017

"Corresponding author: Haitham Talaat, Civil Engineering, Samalout, Minia, Egypt, Email: haithamsrour41@gmail.com

\begin{abstract}
Redundancy is the duplication of a system's components or functions in order to increase its reliability. This system is provided with a pack of duplications of the components for saving backups in case of sudden malfunctioning. A satellite, for instance, is provided with basic duplications before its launch such as inertial navigation system which depends on 5 duplicate computers on the satellite and 3 inertial measurement congruent units.
\end{abstract}

This is the same in living organisms, where genes duplicate in a way that protects them from any sudden mutations or failures. Redundancy is a biological Safety system that destroys the effect of mutations. Redundant mechanisms duty is to achieve the aims of growth in complete perfection. This mechanism is necessary; as there is no system with such complexity as that of living organisms unless it will need the redundancy in its different phases of Decoding.

This Phenomenon imposes a giant challenge to the conception of beneficial mutations. In order to get a beneficial mutation with evident effect, this mutation should have the same semblance and technique in all the redundant copies which produce this effect in a genome. The more redundant the genes are, the more we need synchronizing effective mutations on the progressive change, and the more difficult it is to believe in the ability of this change to get a wholesome model.

This article sheds light on the decisive difficulties which face the hope of inducing any beneficial mutations.

\section{Redundancy Eliminates the Dream of Beneficial Mutations:}

If you change one of the redirecting programs into the Spacecraft, Irrespective of your thinking is it right or not, the other copies will recorrect any damages which may happen because there are always other congruous copies can receive easily the original data with perfect reliability. So, if you decided to modulate the data for better performance in one of the redirecting programs, you should carry out this change discreetly in every copy at the same time and place. Any other attempt will cause a damage in the program in general if your changes take place in different areas of the identical copies, or else your changes will be useless if they were not applied on every copy.

Therefore, Trying to manufacture synthetic mutations in the Drosophila leads to induce only a strange flaw in its shape or function because mutations weren't in the same postures in the same characters [10]. The main condition is that the mutations must be beneficial and in the same place and time or there will be a permanent damage induced.

So if you want to coordinate the conditions to manufacture beneficial mutations, there are specific conditions to follow:
A. 1_ A change in the systematization or semblance of characters.

B. The change of characters must produce beneficial mutations.

C. The change must be applied in the same area.

D. The change must be applied in the same time.

If any of these conditions is deranged, no effect or change happens. So, redundancy eliminates the Dream of beneficial mutations. Redundancy is a duplication in every developmental level Redundancy is not just in the individual genes or in only one of the developmental levels of organisms. It's rather a phenomenon on all levels. As we have already stated, redundancy is not only produced by congruous genetic texture, but by other many substitutes. So, the function of redundancy is performed by congruous several copies and substitutes. The developmental function directs its models to the cell as its object either directly by the Congruous genes or indirect by other ways we don't know much about it [11]. As noted in an Independent Study on genital apparatus by using of hybridization, it turned that genital apparatus is created in different ways and several substitutes of strand of DNA [12]. 
There is, indeed, more problematic issue that the Congruous redundancy isn't just for producing a function of system, but , the functional system turns into producer for other substitutes beside the Congruous copies, so, to manufacture a beneficial mutations you should be acquainted with the offered substitutes then start to apply the above-mentioned four conditions ( requirements).

\section{What's the Exigency of Congruous and Incongruous Redundancy in Organisms?}

Though this question has many Philosophical exigencies it's not a Philosophical , it's mostly an geometrical question. To get developmental target you should have near-zero-error, this high magnitude of the Congruous or incongruous redundancy is necessary, there is no complex system like that in the organisms. This phenomenon poses a radical challenge for the possibility of mutation in the organisms as a result of Successive small mutations.

Assuming that there is a beneficial mutation in the one of the organism's genes must be in compliance with the abovementioned five specific conditions and make simultaneous changes in all the congruous and incongruous copies, therefore whenever the redundancy increases, the Difficulty increases of believe in the ability of mutation to carry out geometric functions.

Assuming that there is a fabrication catalogue for electric lamp has the main components for fabricate it, a lead wire plugs in the filament with an inert gas to protect and class prevent gas or air leakage and lamp cap that plugs in the socket and works as a path for electric current.

This catalogue has many copies so that if one of them has a damage the others keep carry out the same function, by Assuming that there is an additional information of an exact copy that allows to change the result to be a Laser not be an electric lamp, therefore this precious additional information is worthless cause the other copies frustrates its benefit, so, to manufacture a laser you should have synchronous changes in all the copies.

Such a catalogue has many copies so that if one of them is damaged, the others keep carrying out the same function. By Assuming that there is additional information of an exact copy that changes the result to be a Laser not an electric lamp, this precious additional information will be considered worthless because the other copies will frustrate its benefit. So, to manufacture a laser advice, you should have synchronous changes in all the copies.

\section{The sixth condition (additional)}

There is an additional condition that cannot be overlooked; adjusting the other organs of organism to apply the new compensative changes of that organ.

For instance, in order to change an eye of a Mutant bear to whale (The Origin of Species), we need to perform radical changes besides the systematic changes in its eye to cope with the aquatic environment. So, there are radical changes like: changing the visual centre of cerebrum, cerebellum composition, eyelids, durability of the sclera and the ability of that eye on the full of impurities aquatic vision.

This is a real problem to Darwin's theory, when he said: "I can see no difficulty in a race of bears being rendered, by natural selection, more and more aquatic in their structure and habits, with larger and larger mouths, till a creature was produced as monstrous as a whale"[13].

\section{Discussion}

What's The Possibility Of Applying Duplication Mutation Simultaneously In More Than One Redundant Model?

If you believe in the beneficial mutations whereas it's statistically impossible to take place in all redundancies at the same time and format, then hold still that mutation is the source of all biological systems, it has nothing to do with empirical observational science.

If you put a possibility for mutational growth in one of the Nucleotide pairs simultaneously in all the redundancies with the symbolization to that Nucleotide pair with $(\mathrm{N})$, the number of redundancies with $(\mathrm{R})$, to apply it simultaneously by counting the generation's age and the possibility of mutation with $(\mathrm{t})$ there is a need to $(\mathrm{N})$ exponent $(\mathrm{S})$ exponent $(\mathrm{T})$ of the chances.

Assuming that the average of encryption by the simplest functional systems is 100 thousands of base-Nitrogen pairs, the lowest number of Redundancies in no time for the generation regardless about the average of mutation, the ratio won't be enough for the whole universe because the universe's age is 10 exponent $17 \mathrm{sec}$. Whereas the very least possibility for mutation simultaneously in all duplications transcend 100.000 exponent 2 exponent $2 \mathrm{sec}$, that equalizes 10 exponent $20 \mathrm{sec}$ that equalizes billions of the universe's age.

\section{Conclusion}

The scientific objection and mathematical statistics regarding duplication of redundancy destroys the dreams of generating any beneficial functional system. So, if we wait for an appearance of new organisms, it's just an amusing story for children, not an empirical or observational or probable science.

\section{References}

1. James ET (1986) "Digital Fly-By-Wire: A Case of Bidirectional Technology Transfer," in Aerospace Historian 33 (1): 10-18.

2. Roscoe CF, Robert T, Hiram CT (2006) Implementing Space Shuttle Data Processing System Concepts in Programmable Logic Devices.

3. Able KP (1980) Mechanism and orientation, Navigation and Horning in Animal Migration, Academic Press, New York, USA, pp. 59-61.

4. Pérez-Pérez JM, Candela H, Micol JL (2009). Understanding synergy in genetic interactions. Trends Genet. 25 (8): 368-76.

5. Erickson HP (1993) Tenascin-C Tenascin-R Tenascin-X: A Family of Talented Proteins in Search of Functions. Curr Opin Cell Bio 5(5): 869876. 
6. Goldberg ML, Colvin RA, Mellin AF (1989) The Drosophila Zeste Locus is nonessential. Genetics 123(1): 145-155.

7. Sternberg PW (1993) Intercellular signaling and signal transduction in C. efegans. Annu Rev Genet 27: 497-521.

8. Nehrt NL, Clark WT, Radivojac P, Hahn MW (2011) Testing the ortholog conjecture with comparative functional genomic data from mammals. PLoS Comput Biol 7(6): e1002073.

9. Studer RA, Robinson-Rechavi M (2009) How confident can we be that orthologs are similar, but paralogs differ? Trends in Genetics 25(5): 210-216.

10. Gauchat D, Mazet F, Berney C, Schummer M, Kreger S, et al. (2000)
Evolution of Antp-Class Genes and Differential Expression of Hydra Hox/ParaHox Genes in Anterior Patterning. Proc Natl Acad Sci of the USA 97(9): 4493-4498.

11. Wilson SW (1993) Clues from Clueless. Current Biology, pp. 539.

12. Daojun J, Ben-Wen Li, Peter U, Fischer, Gary W (2008) Localization of gender-regulated gene expression in the filarial nematode Brugia malayi International Journal for Parasitology 38 (5): 503-512.

13. Darwin C (1998) The Origin of the Species. Wordsworth Classics of world literature, USA, pp.184.

\section{Your next submission with Juniper Publishers will reach you the below assets}

- Quality Editorial service

- Swift Peer Review

- Reprints availability

- E-prints Service

- Manuscript Podcast for convenient understanding

- Global attainment for your research

- Manuscript accessibility in different formats

(Pdf, E-pub, Full Text, Audio)

- Unceasing customer service

Track the below URL for one-step submission https://juniperpublishers.com/online-submission.php 